\title{
Mine blast injuries: ocular and social aspects
}

Waqar Muzaffar, Muhammad Dawood Khan, M K Akbar, Mohammad Daud Khan, Abdul Majeed Malik, Omar M Durrani

\begin{abstract}
Backgroundlaims-Landmines have long been used in conventional warfare. These are antipersonnel mines which continue to injure people long after a ceasefire without differentiating between friend or foe, soldier or civilian, women or children. This study focuses on Afghan noncombatants engaged in mine clearing operations in Afghanistan in the aftermath of the Russo-Afghan war. The patterns and types of injuries seen are described and experiences in their management, ways, and means to prevent them, and recommendations for the rehabilitation of the affected individuals are given.
\end{abstract}

Methods-It is a retrospective and analytical study of 84 patients aged 19-56 years who sustained mine blast injuries during mine clearing operations in Afghanistan from November 1992 to January 1996. The study was carried out at a military hospital with tertiary care facilities. The patients were divided into three groups on the basis of their injuries. Group 1 required only general surgical attention, group 2 sustained only ocular injuries, while group 3 had combined ocular and general injuries. Patients in groups 2 and 3 were treated in two phases. The first phase aimed at immediate restoration of the anatomy, while restoration of function wherever possible was done in subsequent surgical procedures in the second phase.

Results-It was observed that 51 out of 84 patients $(60.7 \%)$ had sustained ocular trauma of a variable degree as a result of the blasts. The mean age of the victims was 29 years and they were all male. A total of 91 eyes of 51 patients $(89.2 \%)$ had been damaged. Bilaterality of damage was seen in $40(78.4 \%)$ patients. Most, 34 $(37.3 \%)$, eyes became totally blind (NPL). Only a few escaped with injury mild enough not to impair vision. Foreign bodies, small and multiple, were found in the majority of eyes; most, however, were found in the anterior segment, and posterior segment injuries were proportionally less.

Conclusions-The prevalence of blindness caused by mine blast injuries is quite high. The resulting psychosocial trauma to the patients and their families is tremendous and has not been adequately highlighted. These injuries are a great drain on the country's resources. Enforcement of preventive measures and the use of protective gear and sophisticated equipment by the mine clearing personnel would prove to be far more economical in terms of human life as well as medical and economic resources. There is also need for greater attention towards the establishment of support groups and rehabilitation programmes for these individuals.

(Br F Ophthalmol 2000;84:626-630)

Since the cave age, men have been trying to inflict the maximum damage upon their enemies. To achieve this they have strived continuously to develop increasingly deadly weapons. At some point in the process of weapon evolution, it dawned on them that a maimed and crippled enemy soldier had a more demoralising effect on his comrades than a dead one. This crippled soldier also became a continuing drain on his country's medical and economic resources. Landmines are the outcome of application of this philosophy in development of deterrent weapons.

The American Civil War is recorded as the first major conflict where landmines were used on a large scale. The first world war and subsequent wars saw landmines become an essential part of defence against enemy advance and recent years have seen a global increase in their use.

These antipersonnel mines have the potential for injuring both combatants and noncombatants, during and after the conflict. Combatants are at risk when venturing into enemy territory, laying or defusing mines. Non-combatants, including women and children, may be injured when they accidentally step on a mine, or when they are involved in mine clearing operations, as is the case with the subjects in our study.

Most modern mines are made of plastic or other synthetic materials to escape detection..$^{1-3}$ They may be activated by pressure or by means of a tripwire, and are designed to explode releasing a shower of metal fragments or small missiles into the air towards the advancing enemy. Landmines are specifically designed to maim and cripple the enemy, their aim being to increase morbidity rather than mortality.

Mine blasts typically cause peppering of the eye with minute particles, which may be a combination of plastic or metallic particles, gunpowder, sand, dust, and organic debris. ${ }^{34}$ These multiple fragments may be impacted on the eye as superficial foreign bodies or may penetrate the globe, causing a wide spectrum of injuries. 


\section{Materials and methods}

Our study focuses on Afghan non-combatants injured during mine clearing operations in Afghanistan in the aftermath of the RussoAfghan war. These patients were given first aid at the nearest primary care units immediately after the mine blast. They were subsequently brought to the Combined Military Hospital $(\mathrm{CMH})$ Peshawar, which has been designated a referral centre for victims of landmine explosions by the United Nations (UN) and International Committee of the Red Cross (ICRC). Specialised ophthalmic intervention was carried out at this hospital.

In a retrospective analytical study covering the period from November 1992 to January 1996, we studied 84 patients who were admitted to our hospital. We divided the patients into three groups on the basis of their injuries (Fig 1).

Group 1 included patients who required general surgical treatment ranging from simple debridement of wounds to limb amputations; group 2 consisted of patients who had exclusively ocular injuries; and group 3 comprised the remaining patients who sustained both ocular and general injuries.

At the time of arrival a complete history was taken as to the circumstances of injury, first aid was administered, and medication, if any, was given. The general condition of the patient was assessed, life and limb threatening injuries were given first priority, and a general surgeon was consulted. The status of antitetanus immunisation was assessed and necessary drugs administered where indicated.

A complete ophthalmic examination was carried out. Visual acuity was recorded at the time of arrival; ophthalmoscopy and slit lamp examination were performed where possible. An indirect ophthalmoscope was used to visualise the posterior segment where feasible.

B-scan ultrasonography of the eye and orbit was done in cases in which the media were hazy to assess the integrity of the structures lying behind the opaque media. $x$ Ray examination of the orbit was carried out in the anteroposterior, lateral, and oblique views to identify and locate foreign bodies where suspected. Baseline investigations such as blood grouping, cross matching, and complete counts were carried out. $x$ Ray of the chest in the posteroanterior view was done where possible.

The extent and severity of damage to ocular structures was recorded and a treatment strategy was mapped out. General anaesthesia was preferred for debridement as well as surgical

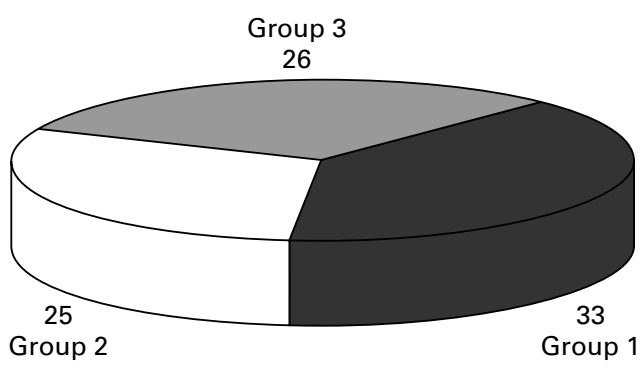

Figure 1 Grouping of patients on the basis of injury.

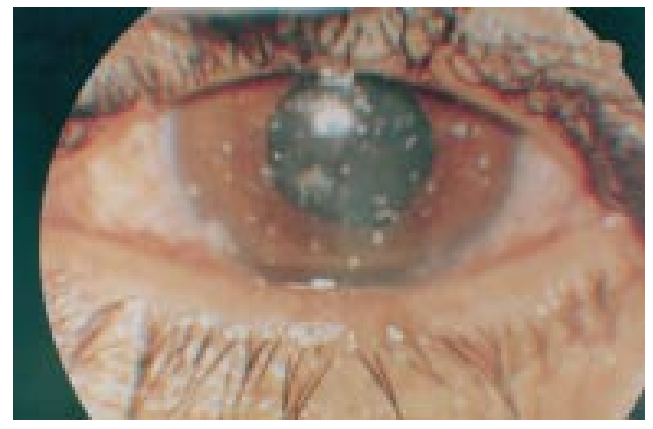

Figure 2 Typical peppering of the cornea with multiple small foreign bodies.

management. Efforts of the ophthalmic and general surgeons were coordinated to enable them to perform their respective surgeries during the same anaesthesia procedure.

The patients were followed up in the outpatient department after discharge from the hospital, and readmitted as and when the next stage of treatment demanded.

\section{Results}

Thirty three patients were in group 1 and were dealt with by the general surgeon. Group 2 consisted of 25 patients with exclusively ocular injuries requiring attention of an ophthalmic surgeon. Group 3 comprised 26 patients who sustained both ocular and general surgical injuries; they were dealt with by both ophthalmic and general surgeons.

We further analysed the 51 patients in groups 2 and 3 and data relating to ophthalmic examination were collected. It was found that 91 eyes of these 51 patients $(89.2 \%)$ had been damaged by mine blast injuries. Forty $(78.4 \%)$ patients had both eyes damaged, whereas 11 $(21.5 \%)$ patients suffered damage to one eye only.

The majority of the patients arrived within 10-30 hours of the occurrence of the blast. The longest delay was 46 hours and the shortest evacuation time was 8 hours. Ages of the blast victims ranged from 19 to 56 years. The mean age was 29 years with the majority of the patients aged between 20 and 29 years. The patients were all male. None of these patients was recorded to be wearing any type of protective gear recommended internationally for such operations.

Most, 34 (37.3\%), eyes became totally blind with no light perception (NPL). A substantial number, $42(46.1 \%)$, were left with visual impairment of varying severity and only a few, $15(16.4 \%)$, escaped with injuries mild enough not to impair vision significantly.

Foreign bodies, small and multiple, were found in a majority of patients (Fig 2). The maximum number were seen on the lids and conjunctiva. The cornea and sclera had been perforated by these foreign bodies, causing ruptured globes in more than half of the cases. Posterior segment injuries were proportionately less compared with those of the anterior segment.

On detailed examination, foreign bodies were found in the lids of $86(94.1 \%)$ eyes, and lid lacerations in $57(62.6 \%)$ eyes. Conjuncti- 
val foreign bodies were found in $71(78 \%)$ eyes and lacerations in $55(60.4 \%)$ eyes. Corneal lacerations were seen in $46(50.5 \%)$ eyes and scleral lacerations in $41(45 \%)$ eyes. The uvea was seen to be prolapsed in $14(15.4 \%)$ eyes whereas hyphaema was present in $34(37.4 \%)$ eyes. Iris tears were seen in $20(22 \%)$ eyes while traumatic cataract developed in 20 $(22 \%)$ eyes. Vitreous haemorrhage was seen to have occurred in $16(17.6 \%)$ eyes. Retinal lesions were found in only seven $(7.7 \%)$ eyes.

\section{Treatment}

The injured patients received first aid at the nearest primary care units. Specialised intervention was carried out at our ophthalmic trauma unit where, apart from the necessary debridement, primary repair of the wounds, and removal of superficial foreign bodies, aggressive antimicrobial therapy was initiated.

The treatment was divided into two phases. Restoration of the anatomy was aimed at in the first phase, while functional restoration was achieved in the second phase by subsequent surgical procedures.

Plastic lid repairs were carried out in 46 $(50.5 \%)$ eyes; eviscerations in $21(23.1 \%)$ and enucleations in four $(4.4 \%)$ eyes; prosthetic implants in seven $(7.7 \%)$ eyes; vitrectomies were performed in $16(17.6 \%)$ and trabeculectomies in four $(4.4 \%)$ eyes; intraocular lenses were implanted in seven $(7.7 \%)$ eyes; rotational and penetrating keratoplasties were done in two $(2.2 \%)$ eyes.

\section{Discussion}

The second world war ended more than half a century ago but armed conflicts continue in over 50 countries around the world. ${ }^{5}$ Some countries have seen conflict for decades: Angola 30 years, Afghanistan 17 years, Sri Lanka 11 years, and Somalia for 7 years. More civilians have been killed since the first world war than combatant soldiers. The main culprits in these killings have been mines and more specifically antipersonnel mines. Inexpensive to lay, each mine costs from $\$ 3-10$, while the cost incurred by the enemy as a result of its effects is disproportionately high. ${ }^{5-7}$ Landmines are deadly and effective from the user's point of view. As one Khmer Rouge general put it "a landmine is a perfect soldier, ever courageous, never sleeps, never misses."

Since 1975 landmines have killed or maimed more than one million people. ${ }^{5}$ They continue

Table 1 Prevalence of total blindness (NPL) due to mine blast injuries

\begin{tabular}{|c|c|c|c|c|}
\hline & \multicolumn{2}{|c|}{ Visual acuity* } & \multirow[b]{2}{*}{ Number of eyes } & \multirow[b]{2}{*}{ Percentage } \\
\hline & Maximum & Minimum & & \\
\hline & $6 / 6$ & & 7 & $7.7 \%$ \\
\hline No impairment & $6 / 9$ & $6 / 18$ & 8 & $8.8 \%$ \\
\hline $\begin{array}{l}\text { Category } 1 \text { (visual } \\
\text { impairment) }\end{array}$ & $6 / 18$ & $6 / 60$ & 5 & $5.5 \%$ \\
\hline $\begin{array}{l}\text { Category } 2 \text { (severe } \\
\text { visual impairment) }\end{array}$ & $6 / 60$ & $3 / 60$ & 7 & \\
\hline Category 3 (blind) & $3 / 60$ & $1 / 60$ & 11 & $12 \%$ \\
\hline Category 4 (blind) & $\mathrm{CF}$ & PL & 19 & $20.8 \%$ \\
\hline Category 5 (blind) & NPL & & 34 & $37.3 \%$ \\
\hline
\end{tabular}

*Adapted from WHO categories of visual impairment. ${ }^{19}$

$\mathrm{CF}=$ finger counting; $\mathrm{PL}=$ perception of light; $\mathrm{NPL}=$ no perception of light. to kill 1000 victims each month and disable 800 others for life. ${ }^{58}$ There are at least 250000 landmine disabled people in the world today and the number is increasing day by day, ${ }^{9}$ as a landmine explodes every 20 minutes somewhere around the world. ${ }^{10}$

There are estimated to be 110 million land mines in 64 countries around the world today. $^{5} 61112$

It is an expensive and laborious process to clear mines-costing from \$300-1000 per mine-with trained workers probing and crawling along inch by inch. One person can cover only 20-50 square metres a day. If all laying of mines is stopped today, it would take 1000 years to completely clear the world. ${ }^{5}$

In Afghanistan alone, there are more than 10 million landmines spread over an area of 466 square kilometres. ${ }^{13}{ }^{14}$ On average, 20 civilians are injured daily by these mines. Over half of the victims die due to lack of medical facilities. More than 361000 livestock have been killed and 9600 vehicles destroyed. Eight nongovernmental organisations employ 3000 people, including our subjects, in mine clearing programmes. They have succeeded in locating and destroying more than 200000 mines up till now. ${ }^{14}$ It is a cause for concern that only 62 square kilometres out of a total of 466 square kilometres have been cleared. Apart from the cost and labour involved, the risk to life, limb, and sight during these operations is tremendous. Our subjects are a living testimony to this fact.

The mean age of the victims was 29 years, which is similar to observations of other researchers working on ocular trauma. ${ }^{15-17}$ The ages ranged from 19-56 years which was thought to be a wide range, but other researchers have also reported ranges of $16-50$ years $^{15}$ and 9-57 years ${ }^{13}$ respectively.

All patients observed in this study were male, as only they are selected for the specific job of mine clearing. Other studies on ocular trauma have also reported male predominance, and figures as high as $95 \%,{ }^{3} 97 \%,{ }^{17}$ and $100 \%{ }^{18}$ have been reported. The higher exposure to outdoor activities and potentially risky occupations have been cited to be the cause of high proportion of ocular trauma in the male sex.

The bilaterality of ocular injuries observed in this study was $78.4 \%$, which is higher than figures of $50-72 \%$ quoted by other similar studies. ${ }^{3}{ }^{15}$ This is explained by the posture and proximity of the victim to the ground which exposes him to the full force of a shower of fragments and debris.

The prevalence of total blindness (NPL) due to mine blast injuries according to category 5 (NPL) of the WHO classification of blindness ${ }^{19}$ was found to be $37.36 \%$ (Table 1). However, if we consider data according to WHO criteria, categories $3(1 / 60)$ and 4 (light perception) also fall under the heading of blindness and the incidence of blindness rises to $73.3 \%$, which approaches figures of $74-75 \%$ quoted by other similar studies. ${ }^{31520}$ The majority of the patients reached our hospital within 10-30 hours of the blast, which compares favourably with previous studies where evacuation times 
ranged from 10-15 hours. ${ }^{21}{ }^{22}$ Speedy evacuation and prompt surgical intervention where indicated was found to have a direct bearing on favourable visual prognosis compared with studies where delay in presentation caused an increase in the degree of complications. A system was devised to alert the surgical staff beforehand, thereby enabling a multispecialty team to proceed without further delay in salvaging the damage as is the practice in other centres. ${ }^{23}$ Hospital mortality was very low, understandably because the more seriously ill died before they could reach the hospital, a fact also recorded by other researchers. ${ }^{1}{ }^{24-26}$

Unfortunately a significant number of eyes were lost as they had been ruptured irretrievably or infection had developed because of a delay in evacuation and initiation of antibiotic therapy, a fact also noted by other researchers. ${ }^{27}$

Charring of the skin and exposed parts is the hallmark of mine blast injuries (Fig 3). We recommend thorough scrubbing with surgical solutions and early debridement of the skin wounds, preferably under general anaesthesia. Delay in removal of these gunpowder fragments and debris from the skin leads to tattooing of the skin and permanent disfigurement.

Small penetrating injuries had a favourable prognosis provided the patient was treated at an early stage. Sizeable perforating wounds presented a guarded prognosis despite aggressive antibiotic therapy.

Intraocular foreign bodies presented the problem of localisation. ${ }^{27}$ Some studies recommend computed tomograph scanning for initial assessment ${ }^{28}$ and localisation ${ }^{23}$ but financial constraints render the suggestion impracticable at our centre. We managed, by various $x$ ray views of the orbit and ultrasonic B scans, both in sitting and lying positions, to locate the foreign body. Extraction was difficult, especially with impacted foreign bodies, but where indicated was best via the entry orifice. ${ }^{27} 29$

Enucleation at an early stage was performed in ruptured eyes with no vision to prevent sympathetic ophthalmia in the other eye, a practice also in use at other centres. ${ }^{30}$ Eviscerations in blind eyes were carried out with a provision for subsequent implant of a silicone ball prosthesis.

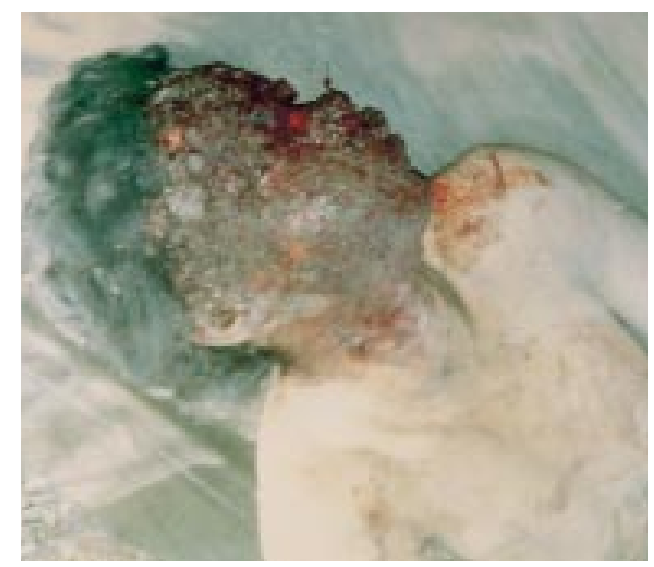

Figure 3 Charring of the skin is the hallmark of mine blast injuries.
An initial decrease in visual acuity in less severe cases was due to oedema of the corneal endothelium, hyphaema, and commotio retinae as a result of concussion. ${ }^{31}$ The visual acuity improved later on with treatment in these cases. A small number of eyes escaped with vision unaffected and required no treatment at all.

The second phase, restoration of function, involved plastic lid repairs, intraocular lens implants, and rotational keratoplasties. Penetrating keratoplasties were reserved for cases with severely damaged corneas.

As in other similar studies, ${ }^{1}$ our experience showed that the majority of eyes were injured by fragments, mud, or sand from the explosion. Many victims lost one eye and suffered a variable degree of damage to the other. A few were totally blinded in both eyes (NPL).

It was recorded that none of the victims was wearing protective eyegear or clothing. Such apathy is common ${ }^{30}$ and is to be viewed seriously because occupational injuries, although common, are preventable provided suitable precautions are taken. ${ }^{16}$ This lapse in enforcement of comparatively economical measures costs the society dearly in terms of loss of manpower, drain on surgical resources, and supportive and rehabilitative measures for the victims.

Based on our observations and experiences we offer the following recommendations:

(a) A complete global ban on the production and use of land mines in the full spirit of the Ottawa Convention.

(b) Use of considerably better protective equipment for the mine clearing staff including helmets with reinforced Plexiglass visors, padded jackets and knee pads, and air cushion shoes to reduce the risk of accidentally activating mines and to afford better protection in case of that eventuality.

(c) The use of trained dogs and electronic equipment to detect and locate mines.

(d) The use of mechanical minesweepers instead of human personnel.

(e) An improved and speedy evacuation system to the nearest specialised ophthalmic and trauma unit.

(f) Increased efforts and facilities for the victims' rehabilitation as follows:

(I) Visual: by offering the best possible surgical equipment and expertise to salvage and restore vision.

(II) Social: by educating their families and friends to look after and accept them into the society as individuals and not as cripples.

(III) Occupational: by providing the individual opportunities for learning a trade, craft, or skills with which he can sustain himself and his family and earn his livelihood.

The International Campaign to Ban Landmines (ICBL) under the leadership of Jody Williams succeeded in December 1997 in drafting a treaty to ban landmines. It came to be known as the Ottawa Convention or Mine Ban Treaty. Over 130 countries have signed the 
treaty and 40 have ratified it. Mine laying continues in countries that have signed but not ratified the treaty. The United States has still not signed the treaty, stating a goal of 2006 for signing it. ${ }^{32}$

On 1 March 1999 the Ottawa Convention became binding international law for every country that had ratified it. It comprehensively bans all antipersonnel mines, requires destruction of stockpiled mines within 4 years, requires destruction of mines already in the ground within 10 years, and urges extensive programmes to assist victims of landmines.

The human aspect of the plight of landmine victims was brought to the attention of the world by the efforts of Princess Diana in her last days. In the words of Cornelio Somaruga, President of the ICRC, "real success of the treaty will be measured in terms of fewer victims, replanting of fertile farmland and resumption of normal life in communities plagued by landmines". ${ }^{33}$

This article is dedicated to the memory of Diana, Princess of Wales, who in her life rendered great service to the cause of landmine victims and brought home to the world awareness of the human aspect of the tragedy.

1 Coupland RM, Korver A. Injuries from antipersonnel mines the experience of the International Committee of the Red Cross. BMF 1991;303:1509-12.

2 Duocet I. The coward's war. Landmines and civilians. Medicine and War 1993;9:304-16.

3 Jackson H. Severe ocular trauma due to landmines and other weapons in Cambodia. Commun Eye Health 1997;10 other

4 Quere MA, Bouchat J, Cornand G. Ocular blast injuries. Am 7 Ophthalmol 1969;67:64-9.

5 UNICEF report. UNICEF launches anti-war agenda. Press summary, 1996.

6 Masland T, Barry J. Buried terror. Newsweek 1996;Apr 8:28-31.

7 US Department of State. Hidden killers: the global problem with uncleared landmines. Report on international demining. Washington, DC: US Department of State, 1993.

8 International Committee of the Red Cross. International review of the Red Cross. Geneva: ICRC, 1994.

9 Roberts S, Williams J. After the guns fall silent: the enduring legacy of landmines. Washington, DC: Vietnam Veterans of America Foundation, 1995.

10 United States Department of State. Bureau of Political-
Military Affairs. Hidden killers, the global landmines crisis. Washington, DC: United States Department of State, 1994:1.

11 Kakar F. Direct and indirect consequences of landmines on public health. Geneva: World Health Organisation, 1995.

12 Human Rights Watch. Landmines: a deadly legacy. New York: The Arms Project, 1993:51.

13 Whitehead B. VISA in Afghanistan. Community Eye Health 1997;10:44-5.

14 UNOHCA Publication. MCPA report, 1995

15 Zerihun N. Blast injuries of the eye. Tropical Doctor 1993;23: $76-8$.

16 Dannenberg AL, Parver LM, Brechner RJ, et al. Penetration eye injuries in the workplace. The National Eye Trauma System Registry. Arch Ophthalmol 1992;110:843-8.

17 Henderson D. Ocular trauma: one in the eye for safety glasses. Arch Emerg Med 1991;8:201-4.

18 Marshall DH, Brownstein S, Addison DJ, et al. Air guns: the main cause of enucleation secondary to trauma. Can 7 Ophthalmol 1995;30:177-8.

19 World Health Organisation. International stastical classification of diseases and related health problems. Tenth revision. Geneva: WHO, 1992.

20 Wong RF, Colin MA, Ryan SJ. Pathophysiology of posterior segment trauma. Eye trauma. St Louis: Mosby Year Book, 1991:204-10.

21 Hasnain SQ, Kirmani M. A 5 year retrospective case study of penetrating ocular trauma at the AKUH Karachi. $\mathcal{F} \mathrm{Pak}$ Med Assoc 1991;41:189-91.

22 Triester G. Ocular casualties in the 6 day war. Am $\mathcal{f}$ Ophthalmol 1969;68:669-75.

23 Holt GR, Holt JE. Management of orbital trauma and foreign bodies. Otolaryngol Clin N Am 1988;21:35-52.

24 Davies P, Dunlop N. War of the mines. Cambodia, landmines and the impoverishment of a nation. Colorado: Pluto Press, 994.

25 Khan MD, Kundi N, Mohammed Z, et al. Ocular war trauma in Afghan refugees of Russian invasion. Pak $\mathcal{F} O p h$ thalmol 1987;3:75-8.

26 Hull JB, Bowyer GW, Cooper GJ, et al. Pattern of injury in those dying from traumatic amputation caused by bomb blast. Br F Surg 1994;81:1132-5.

27 Heimann K, Lemman KD. Perforating eye injuries with multiple intra-ocular foreign bodies following military maneuvere accidents. Klin Monatsbl Augenheilkd 1986;188: $221-4$.

28 Origitano TC, Miller CJ, Izquierdo R, et al. Complex cranial base trauma resulting from recreational firework injuries. Case reports and review of literature. Neurosurgery 1992;30:570-6.

29 Cantaloube D, Rives JM, Paulus C, et al. Intra-orbital explosion of a rocket. Rev Stomatol Chir Maxillofac 1988;89:248-

30 Mieler WF, Nanda SN, Wolf MD, et al. Golf related ocular injuries. Arch Ophthalmol 1995;113:1410-13.

31 Cilius GW, Weingeist TA, Krachmer JH. Traumatic corneal endothelial rings. Arch Ophthalmol 1978;96:485-8.

32 International Campaign to Ban Landmines. Landmine treaty ratified by 40 countries in record time. ICBL press release, 17 Sept 1998.

33 International Committee of the Red Cross. Milestone ratification of Ottawa Treaty. ICRC press release 98/34, 17 Sept 1998. 